\title{
PENGGUNAAN MEDIA SOSIAL (YOUTUBE) SEBAGAI MEDIA INOVATIF DALAM PEMBELAJARAN DI MADRASAH GRESIK
}

\author{
Oleh: \\ Abdulloh Abdulloh ${ }^{1}$, Mochamad Zakki Fahmi ${ }^{2}$, Imam Siswanto ${ }^{3}$ \\ ${ }^{1,2,3}$ Departemen Kimia Fakultas Sains dan Teknologi Universitas Airlangga \\ 1abdulloh@.fst.unair.ac.id
}

\begin{abstract}
Abstrak
Telah dilakukan kegiatan pengabdian kepada masyarakat di Madrasah Aliyah Masyhudiyah Gresik. Tujuan pengabdian adalah: 1) memberikan pemahaman kepada guru-guru dalam pembuatan materi pembelajaran melalui YouTube, 2) memberikan motivasi kepada guru, 3) membangun kepercayaan diri para guru, dan 4) menggunakan YouTube untuk sarana pembelajaran yang menyenangkan. Metode kegiatan adalah ceramah, demontrasi, workshop dan pelatihan menggunakan aplikasi Camtasia. Teknik pengambilan data adalah berdasarkan hasil pretest - posttest dan pendekatan partisipasif. Analisis data untuk mengukur kategori keberhasilan dilakukan dengan menghitung persentase jawaban yang benar tiap aspek yang ditanyakan, presentase video pembelajaran yang dibuat dan jumlah video pembelajaran yang telah di upload. Hasil dari kegiatan adalah: 1) pemahaman guru dalam membuat konstruksi materi pembelajaran berbasis video rerata meningkat $52 \%$, 2) $100 \%$ guru telah membuat video untuk media pembelajaran menggunakan aplikasi Camtasia, 3) 30\% guru telah meng-upload video pembelajaran pada media sosial YouTube. Kegiatan ini menghasilkan peningkatan pemahaman guru terkait pentingnya penggunaan YouTube sebagai media pembelajaran dan video yang berisi materi pembelajaran hasil karya guru madrasah.
\end{abstract}

Kata Kunci: youtube, media pembelajaran inovatif, camtasia dan madrasah Gresik

\section{Abstract}

The community service activities have been carried out at Madrasah Aliyah Masyhudiyah Gresik. The purpose of service is: 1) providing understanding to teachers in making learning material through YouTube, 2) providing motivation to teachers, 3) building teachers' confidence, and 4) using YouTube for fun learning tools. Methods of activities are lectures, demonstrations, workshops and training using the Camtasia application. Data collection techniques are based on the results of the pretest - posttest and participatory approach. Data analysis to measure the success category is done by calculating the percentage of correct answers for each aspect asked, the percentage of learning videos made and the number of learning videos uploaded. The results of the activities are: 1) the teacher's understanding in making construction of video-based learning materials on average increased by $52 \%$, 2) $100 \%$ of teachers have made videos for learning media using the Camtasia application, 3) 30\% of teachers have uploaded learning videos on social media YouTube This activity resulted in an increase in teacher understanding related to the importance of using YouTube as a learning medium and videos containing learning materials created by madrasa teachers.

Keywords: youtube, innovative learning media, camtasia, madrasah Gresik

\section{PENDAHULUAN}

Materi pelajaran di madrasah (sekolah) tersusun secara hirarki mulai dari konsepkonsep dasar sampai pada konsep-konsep yang kompleks. Jika siswa dapat mengkaitkan antara konsep satu dengan konsep lainnya, maka siswa tersebut telah memiliki pemahaman yang utuh akan konsep tersebut, jika tidak akan menyebabkan proposisi yang salah sehingga menimbulkan terjadinya kesalahan dalam memahami konsep. Suatu pemahaman konsep menurut pandangan pembelajaran generatif akan terbentuk dalam ingatan apabila terjadi hubungan bermakna antara informasi baru dengan struktur kognitif yang telah ada. Konsep yang baru terbentuk akan dievaluasi dan diuji dengan aspek ingatan yang lainnya yang pada akhirnya dapat dipahami (Mawaddah dan Anisah, 2015).

Memahami materi pelajaran secara utuh bagi kebanyakan siswa terasa agak sulit. Ini 
dapat dimaklumi karena kemampuan konsentrasi siswa untuk tetap fokus pada materi pembelajaran bervariasi (Halil dkk., 2015). Apalagi terhadap materi pelajaran yang membutuhkan konsentrasi tinggi untuk memahaminya, seperti pelajaran kimia, matematika, biologi dan fisika. Salah satu upaya untuk bisa memudahkan siswa belajar adalah "menghadirkan" guru sesering mungkin. Kehadiran guru tentu saja dibatasi dengan jam-jam resmi yang berlaku di sekolah. Dengan demikian kehadiran guru secara nyata tidak mungkin melebihi dari apa yang saat ini berlaku di sekolah (Purwanti, 2015).

Untuk menambah jam guru, maka pertemuan secara virtual saat ini sangat memungkinkan dengan berkembangnya teknologi informasi. Makin terjangkaunya gadget berteknologi canggih dan makin murahnya harga paket konten internet sangat memungkinkan untuk dimanfaatkan sebagai media pertemuan virtual siswa-guru (Gunawan dkk., 2013).

Pertemuan virtual antara siswa-guru yang dimaksud adalah bahwa siswa dapat mengulang pelajaran yang telah disampaikan sebanyak yang dia inginkan, atau siswa bisa juga mempelajari bahan yang akan diajarkan oleh guru sehingga pertemuan di kelas lebih banyak berisi diskusi antara siswa-guru. Salah satu bentuk pertemuan virtual seperti itu adalah tersedianya video pengajaran oleh guru mata pelajaran secara audio visual (Jaya, 2012).

Pembuatan video pengajaran tidak harus membutuhkan perangkat yang sangat mahal. Dengan perangkat computer dengan processor Core i3 saja sudah dimungkinkan untuk membuat video pengajaran. Perangkat lunak pembuatan video juga ada yang tidak terlalu berat misalnya Camtasia Studio. Penelitian terkini menyebutkan bahwa panjang video tidak lebih dari 10 menit masih nyaman untuk ditonton. Hal ini menguntungkan karena video pengajaran dapat dibuat sesuai dengan sub topik yang ada sehingga durasi video tidak perlu hingga setengah bahkan 1 jam.

Kendala teknis yang bakal dihadapi untuk membuat terobosan seperti ini adalah skill dalam bidang video editing (Sugihartini dkk., 2017) dan tempat menyimpan media agar bisa dimanfaatkan oleh orang siswa. Tempat menyimpan dapat diatasi dengan memanfaatkan layanan public tak berbayar seperti Youtube. Sedangkan untuk skill maka diperlukan pelatihan khusus meskipun sederhana tentang bagaimana memulai membuat video pengajaran.

Berdasarkan latar belakang permasalahan di atas, maka perlu adanya peningkatan skill tambahan guru untuk berani membuat media pembelajaran. Upaya peningkatan skill tersebut utamanya ditujukan kepada guru sebagai narasumber melalui pemberian bentuk pelatihan pembuatan video pengajaran dan bagaimana mengorganisir video yang terbentuk agar dapat diakses melalui media sosial Youtube.

\section{METODE}

Metode pelaksanaan pengmas adalah ceramah, workshop, simulasi dan pendampingan pembuatan media pembelajaran dalam video yang bisa diupload dalam media sosial YouTube. Saat simulasi dan pendampingan pembuatan video pembelajaran, peserta pelatihan dibagi menjadi 15 kelompok terdiri dari 3 orang guru dan diberi tugas untuk berlatih menggunakan aplikasi program Camtasia. Instalasi program Camtasia dipandu oleh tim pengmas yang merupakan dosen-dosen kimia Universitas Airlangga (Unair).

\section{HASIL DAN PEMBAHASAN}

\section{Pelaksanaan}

Kegiatan pengabdian kepada masyarakat (pengmas) ini telah dilaksanakan pada hari Jumat dan Sabtu, tanggal 10 dan 11 Agustus 2017 di Madrasah Aliyah Masyhudiyah Gresik. Kegiatan ini dihadiri oleh 45 peserta. Acara ini diawali dengan sambutan dan perkenalan tim pengmas oleh tim dosen Departemen Kimia Universitas Airlangga (Gambar 1) dan sambutan Ketua Yayasan Masyhudiyah Gresik (Gambar 2). Selanjutnya acara pengmas dilakukan sesuai dengan jadwal yang telah disusun (Tabel 1).

Pemateri (nara sumber) pengmas ini adalah dosen-dosen Departemen Kimia yang memiliki kepakaran di bidang media pembelajaran. Dalam materi ini dijelaskan, mengenai metode menyisipkan audio pada materi pembelajaran yang telah dibuat dalam bentuk soft file presentasi sehingga menjadi video pembelajaran yang bisa di upload pada YouTube. 
Tabel 1. Jadwal kegiatan penggunaan media sosial (YouTube) sebagai media inovatif dalam pembelajaran di madrasah gresik

\begin{tabular}{clc}
\hline 10 Agustus 2018 & \multicolumn{1}{c}{ Kegiatan } & Pelaksana \\
\hline $13.00-13.30$ & Registrasi & Tim Unair \\
\hline $13.30-13.50$ & $\begin{array}{l}\text { Pembukaan dan Sambutan-sambutan } \\
\text { 1. Ketua Pengmas Kimia Unair } \\
\text { 2. Ketua Yayasan }\end{array}$ & Tim Unair + Tim Masyhudiyah \\
\hline $13.50-14.00$ & $\begin{array}{l}\text { Paparan program Magister Kimia Universitas } \\
\text { Airlangga }\end{array}$ & Tim Unair \\
\hline $14.00-14.10$ & Pre-Test & Tim Unair \\
\hline $14.10-14.20$ & Coffee Break & Tim Masyhudiyah \\
\hline $14.10-15.30$ & Peng-Instal-an Program & Tim Unair \\
\hline $15.30-16.00$ & \begin{tabular}{l} 
Pemaparan Media Pembelajaran dan Media \\
\multicolumn{1}{c}{ Sosial }
\end{tabular} & Tim Unair \\
\hline $\mathbf{1 1}$ Agustus 2018 & \multicolumn{1}{c}{ Kegiatan } & Pelaksana \\
\hline $08.30-08.50$ & Registrasi & Tim Unair \\
\hline $08.50-09.00$ & Coffee Break & Tim Masyhudiyah \\
\hline $09.00-09.30$ & Pembuatan video pembelajaran menggunakan & Tim Unair \\
\hline & Camtasia & Tim Unair \\
\hline $09.30-09.45$ & Membuat akun Google & Tim Unair \\
\hline $09.45-10.00$ & Membuat channel YouTube & Tim Unair \\
\hline $10.00-10.15$ & Mengupload video pembelajaran ke YouTube & Tim Unair \\
\hline $10.15-10.45$ & Pembuatan video dari PowerPoint & Tim Unair \\
\hline $10.45-11.45$ & Merekam pengajaran menggunakan HP & Tim Masyhudiyah \\
\hline $11.45-13.00$ & ISHOMA & Tim Unair \\
\hline $13.00-14.00$ & Video editing menggunakan Camtasia & Tim Unair \\
\hline $14.00-14.30$ & Membuat akun Google dan channel YouTube & Tim Unair \\
\hline $14.30-15.00$ & Upload video ke YouTube & Tim Masyhudiyah \\
\hline $15.00-15.10$ & Coffee Break & Tim Unair \\
\hline $15.10-15.20$ & Post-Test & Tim Unair + Tim Masyhudiyah \\
\hline $15.20-15.00$ & Penutupan & \\
\hline & &
\end{tabular}

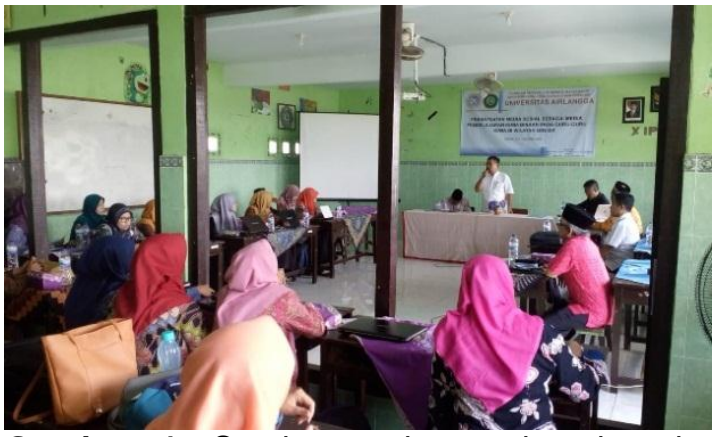

Gambar 1. Sambutan dan perkenalan tim pengmas Departemen Kimia

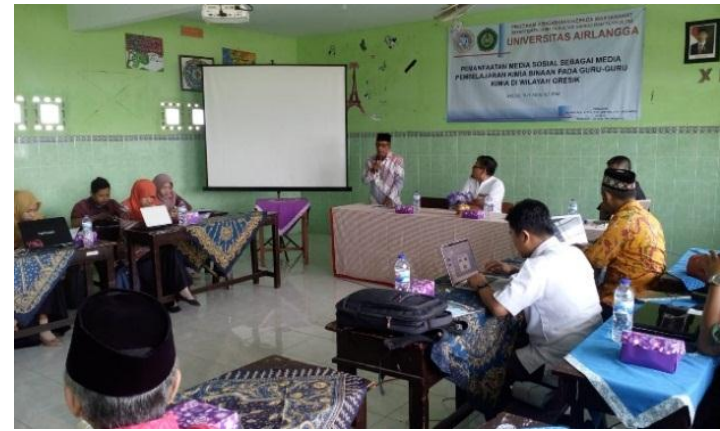

Gambar 2. Sambutan ketua Yayasan Masyhudiyah Gresik 
Selama kegiatan, para peserta sangat antusias dan serius mendengarkan pemaparan materi Media Pembelajaran dan Media Sosial (Gambar 3), sehingga banyak peserta yang berdiskusi secara langsung selama simulasi dan pendampingan pembuatan video pembelajaran dengan nara sumber (Gambar 4).

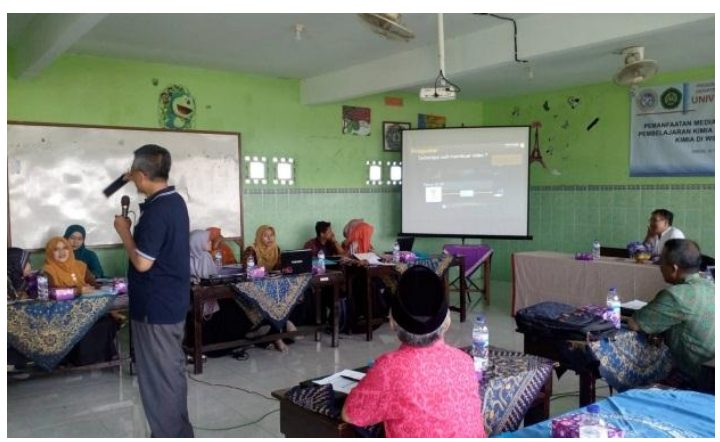

Gambar 3. Nara sumber memberikan pemaparan materi Media Pembelajaran dan Media Sosial

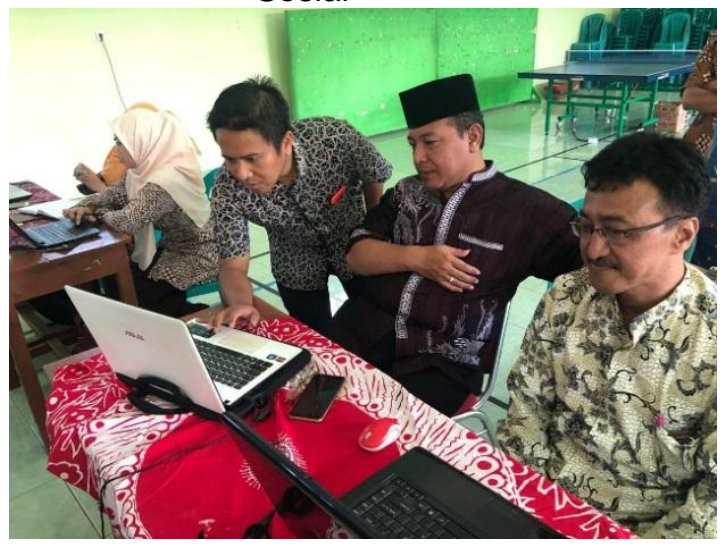

Gambar 4. Nara sumber melakukan simulasi dan pendampingan pembuatan video pembelajaran sambil berdiskusi

\section{Hasil yang Dicapai}

Berdasarkan respon (jawaban) peserta pada pertanyaan dalam pretest-posttest yang disusun oleh tim pengmas (Tabel 2). Rerata pemahaman peserta dalam membuat konstruksi materi pembelajaran berbasis video meningkat dari $34 \%$ menjadi $87 \%$ atau bertambah sebesar 53\% (Gambar 5). Tingkat pemahaman peserta terkait konstruksi video pembelajaran sebelum kegiatan ini relatif rendah. Hal ini disebabkan karena mayoritas peserta adalah guru-guru yang saat menempuh pendidikan relatif kurang berinteraksi dengan aplikasi yang ada di komputer terutama yang berkaitan dengan video.

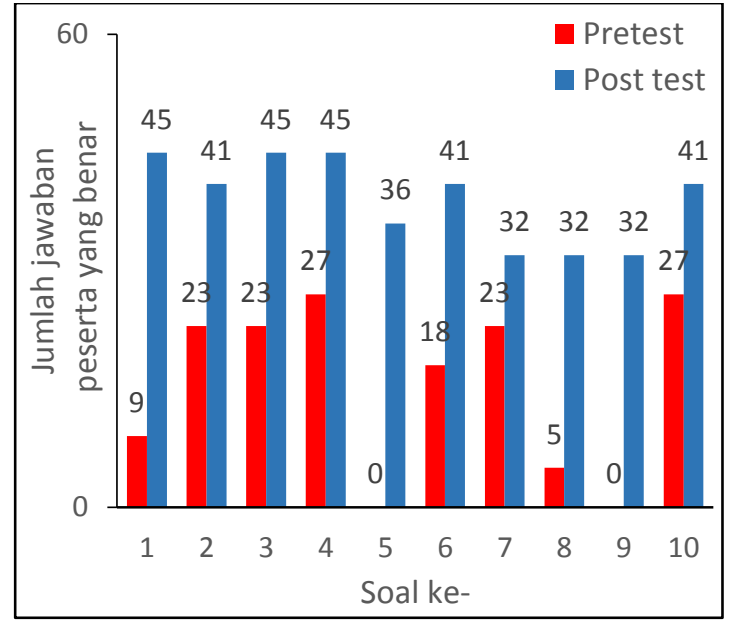

Gambar 5. Hasil pretest-posttest peserta pengmas

Pada akhir kegiatan ini, semua peserta (100\%) peserta telah berhasil menyisipkan audio (suara)-nya dalam media pembelajaran yang telah mereka siapkan dalam bentuk soft file presentasi. Akan tetapi hanya 30\% berani mengupload hasil karyanya meskipun semua peserta sudah diajarkan dan membuat akun google pada YouTube. Berikut adalah salah satu link video media pembelajaran yang saat itu telah diupload peserta (Gambar 6).

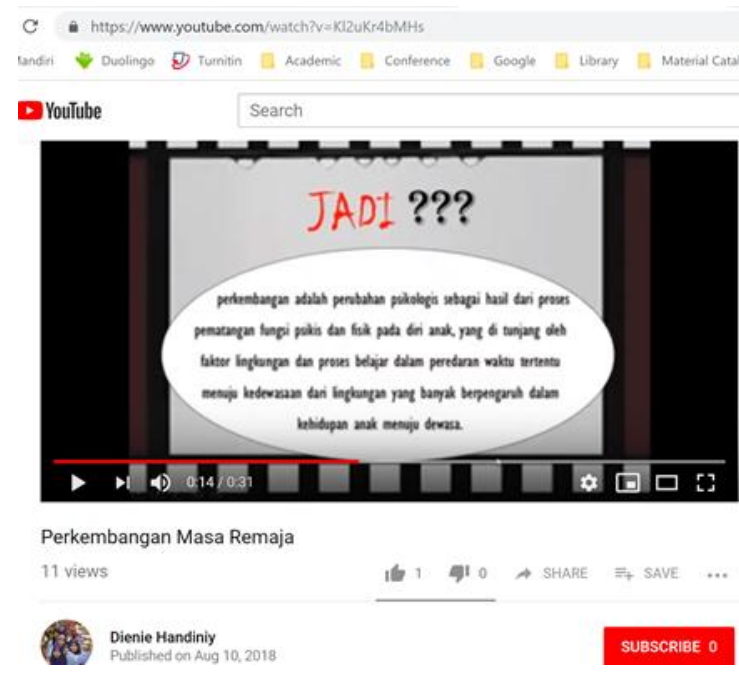

Gambar 6. Video pembelajaran hasil pengmas yang telah diupload 
Beberapa hal yang dikemukakan peserta terkait dengan "positifnya" kegiatan ini adalah:

a. 36 peserta $(80 \%)$ menyatakan bahwa kegiatan ini "Bermanfaat" Madrasah. dan sebanyak 9 peserta (20\%) mengatakan bahwa kegiatan ini "Sangat bermanfaat" untuk membantu guru membuat media pembelajaran dengan video.

b. Menurut peserta, kegiatan workshop dan pelatihan ini merupakan ilmu baru untuk membuat media pembelajaran (23 orang atau $51 \%$ ) dan dapat mengaplikasikan pada pembuatan perangkat pembelajaran (27 orang atau $60 \%$ )

c. Hal-hal yang membedakan kegiatan workshop ini dengan kegiatan workshop yang pernah diikuti peserta sebelumnya adalah: langsung praktek (23 guru), adanya tutorial yang jelas pada workshop ini (20 org) dan pemandu atau instruktur menyenangkan dan telaten (32 orang)

d. Kegiatan yang diinginkan peserta terkait peningkatan kualitas guru adalah: kegiatan workshop aplikasi yang berkelanjutan (41 orang atau 91\%), waktu workshop dan pelatihan ditambah sehingga banyak materi yang diperoleh (5 orang atau $11 \%$ ), workshop materi lain yang mendukung profesi guru (pembekalan materi olimpiade untuk siswa dan lain-lain) sebanyak 18 orang (40\%).

e. Waktunya kurang sehingga perlu ditambah satu atau dua hari lagi untuk simulasi dan pendampingan sebanyak 25 orang (56\%).

f. Nara sumber sabar dan jelas dalam menyampaikan sebanyak 34 orang $(76 \%)$

g. Sebaiknya diadakan lagi sebanyak 41 orang (915)

Berdasarkan jawaban peserta dalam angket, berarti indikator keberhasilan pelaksanaan kegiatan telah terpenuhi, sehingga dapat disimpulkan bahwa kegiatan ini berhasil mencapai tujuan yang ditetapkan.

\section{SIMPULAN DAN SARAN}

Berdasarkan hasil dan pembahasan yang telah diuraikan, dapat disimpulkan, bahwa secara umum, para peserta memberi respons positif terhadap pelaksanaan kegiatan pelatihan penggunaan media sosial (YouTube) sebagai media inovatif dalam pembelajaran dengan aplikasi Camtasia untuk menyiapkan video pembelajarannya.

\section{Saran}

Secara umum, dalam rangka peningkatan profesionalitas guru, dan secara khusus dalam rangka meningkatkan kemampuan guru dalam menggunakan aplikasi Camtasia untuk menyiapkan video pembelajaran pada masa mendatang, kegiatan pemantapan dan workshop semacam ini hendaknya dapat mengakomodasi harapan peserta, yang antara lain, perlu tindak lanjut, perlu penambahan waktu, materi dibuat lebih menyenangkan, dilakukan secara berkala setiap tahun.

\section{DAFTAR PUSTAKA}

Gunawan, G., Setiawan, A. and Widyantoro, D. H. (2013) Model virtual laboratory fisika modern untuk meningkatkan keterampilan generik sains calon guru, Jurnal Pendidikan dan Pembelajaran (JPP), 20(1), pp. 25-32.

Halil, A., Yanis, A. and Noer, M. (2015) Artikel Penelitian Pengaruh Kebisingan Lalulintas terhadap Konsentrasi Belajar Siswa SMP N 1 Padang, Jurnal Kesehatan Andalas, 4(1), pp. 53-57.

Jaya, H. (2012) Pengembangan laboratorium virtual untuk kegiatan paraktikum dan memfasilitasi pendidikan karakter di SMK, Jurnal Pendidikan Vokasi, 2(1), pp. 81-90. doi: 10.21831/jpv.v2i1.1019.

Mawaddah, S. and Anisah, H. (2015) Kemampuan pemecahan masalah matematis siswa pada pembelajaran matematika dengan menggunakan model pembelajaran generatif (generative learning) di SMP, EDUMAT: Jurnal Pendidikan Matematika, 3(2), pp. 166-175.

Purwanti, B. (2015) Pengembangan Media Video Pembelajaran Matematika dengan Model Assure, Jurnal Kebijakan dan Pengembangan Pendidikan, 3(1), pp. 42-47.

Sugihartini, N., Agustini, K., Pradnyana, I. M. A. (2017) Pelatihan video editing tingkat SMK se-kota Singaraja, Jurnal Widya Laksana, 6(2), pp. 172-180. 
Abdulloh, dkk., Penggunaan Media Sosial .... 